\title{
A célula no ensino de biologia: papel do livro didático e concepções de ensino
}

\author{
Mariane Beatriz Karas*, Erica do Espirito Santo Hermel ${ }^{\star \star}$
}

\section{Resumo}

A célula é a menor unidade estrutural e funcional dos diferentes organismos vivos, sendo capaz de existir de maneira independente. Todos os seres vivos são formados por uma ou várias células que são extremamente pequenas; desta forma, só é possível analisar, compreender e estudar com o auxílio de um microscópio. Os livros didáticos são uma das ferramentas mais utilizadas nas escolas, tanto pelos alunos quanto pelos professores. O conteúdo de biologia celular é apresentado de maneira detalhada e ricamente ilustrada nos livros didáticos; assim, torna-se imprescindível conhecer o que as pesquisas recentes apontam sobre o estudo da biologia celular mediado pelo livro didático. Para isso, a presente pesquisa de caráter bibliográfico-documental analisou as concepções de ensino de biologia celular e o papel atribuído ao livro didático em oito dissertações e três teses. Sobre as concepções de ensino houve predominância da concepção emancipatória, seguida da prática. Não houve indícios da concepção técnica. Os resultados apontam para uma tendência de ensino pautada na interação entre os sujeitos mediada por processos reflexivos. Com relação ao papel atribuído ao livro didático, foi possível identificar que os trabalhos expressam que ele tem função referencial e instrumental, ou seja, o papel do livro didático é pôr em prática métodos de aprendizagem com atividades e exercícios, sendo ele um fiel tradutor do programa curricular.

Palavras-chave: biologia celular, currículo, ensino de ciências.

\footnotetext{
Mestranda do Programa de Pós Graduação em Ensino de Ciências (PPGEC), Universidade Federal da Fronteira Sul, Campus Cerro Largo, RS (UFFS/Brasil). E-mail: marianekaras@gmail.com

* Professora do Quadro Permanente do Programa de Pós-Graduação em Ensino de Ciências (PPGEC), Universidade Federal da Fronteira Sul (UFFS), campus Cerro Largo. Doutora em Ciências Biológicas: Neurociências/ UFRGS. E-mail: ericahermel@uffs.edu.br
} 


\section{Introdução}

A célula é a unidade básica da vida, é nela que ocorrem as reações químicas essenciais para a manutenção do metabolismo dos seres vivos (JUNQUEIRA; CARNEIRO, 2012). Contudo, esses processos e reações ocorrem a nível microscópico. Assim, o entendimento desses acontecimentos limita-se à imaginação, o que os torna relativamente abstratos. $\mathrm{O}$ entendimento acerca da biologia celular é essencial para a compreensão e organização do conhecimento biológico, sendo necessário que os alunos compreendam a célula como uma estrutura funcional fundamental para a constituição dos organismos vivos.

O estudo da célula tem seu início no Ensino Fundamental, vinculado à disciplina de Ciências, e sua continuação no Ensino Médio, na disciplina de Biologia. Um ensino significativo dessa temática proporciona a compressão de diversos temas presentes no nosso dia a dia e nos meios de comunicação, como, por exemplo, o câncer, células-tronco, clonagem, entre outros.

Atrelado à necessidade de um ensino significativo no que tange à temática biologia celular, deparamo-nos com as discussões acerca dos diferentes tipos de concepções utilizadas no ensino. Segundo Rosa e Schnetzler (2003), estas concepções são reflexo das influências nas ideias e nas construções dos grupos sobre os muitos níveis de investigação educativa e de possibilidades de desenvolvimento a partir de interação entre sujeitos da educação.

Assim, é possível entendermos a interação entre alunos e professores mediada pelo livro didático (LD) e como esse processo se constitui na aprendizagem como um todo, abrangendo, por exemplo, conceitos sobre biologia celular que possibilitem mais contextualização entre teoria e prática.

Muitas escolas possuem acesso aos mais diversos recursos didáticos e tecnológicos e, mesmo assim, o LD ainda é uma das ferramentas mais utilizadas para o ensino de Ciências (AMARAL; MEGID NETO, 1997; GUIMARÃES; MEGID NETO; FERNANDES, 2011). Sendo que, em algumas escolas, o livro configura-se como o único recurso disponível para que o professor possa ministrar sua aula (OCCELI; VALEIRAS, 2013). Corroborando com Nuñez (2003) e Díaz (2011), que consideram o LD como sendo a principal fonte de trabalho e difusão dos conteúdos curriculares em sala de aula. 
Compreendemos que, hoje, no campo da educação existem diferentes metodologias e ferramentas tecnológicas para que o aluno possa compreender de forma significativa a biologia celular; apesar disso, o livro didático ainda é um dos recursos mais utilizados nas escolas. A descrição oferecida por Vasconcelos e Souto (2003, p. 93-94) elucida a importância dos LDs: "[...] no ensino de ciências, os livros didáticos constituem um recurso de fundamental importância, já que representam em muitos casos o único material de apoio didático disponível para alunos e professores”. Assim, o LD pode ser, muitas vezes, o único livro com o qual o estudante tenha contato, além de ser uma das únicas ferramentas de apoio do professor, constituindo-se numa importante fonte de estudo e pesquisa.

Ainda, Occeli e Valeiras (2013) destacam que o LD tem desempenhado, desde longa data, um importante papel no ambiente escolar, constituindo-se em uma base para os professores. Em busca de um processo de ensino e aprendizagem significativo e compreensível, diversas modalidades didáticas também poderiam ser empregadas.

Nesse sentido, o LD pode assumir funções variadas, dependendo das condições, do lugar e do momento em que é produzido e utilizado nas diferentes situações escolares. Choppin (2004) identificou quatro funções que os LDs assumem em sala de aula, conjuntamente ou não. Na função referencial, o LD possui um caráter de ser fiel tradutor do programa curricular. Na função instrumental, o livro põe em prática métodos de aprendizagem com atividades e exercícios. Quanto à função ideológica e cultural, o LD funciona como um vetor de tentativa de afirmação da língua, da cultura e dos valores das classes dirigentes. E, por fim, esse material didático apresenta a função documental, proporcionando elementos que, interpretados pelos estudantes, favorecem o desenvolvimento de seu senso crítico.

Os LDs de Ciências e de Biologia abordam a biologia celular de maneira ilustrada e detalhada, sendo, portanto, uma fonte de aproximação dos alunos com essa temática. Desse modo, o estudo do LD é fundamental para uma análise mais profunda sobre a natureza e a qualidade do processo de ensino e de aprendizagem. Assim, essa investigação trata de uma pesquisa bibliográfico-documental que objetiva identificar as concepções de ensino (ROSA; SHENETZLER, 2003) e o papel atribuído ao LD (CHOPPIN, 2004) nas pesquisas recentes sobre biologia celular nos LDs. 


\section{Metodologia}

A presente pesquisa em Ensino de Ciências seguiu uma abordagem qualitativa, mediante uma análise bibliográfico-documental (LUDKE; ANDRÉ, 2001). Foi realizada uma revisão da literatura em trabalhos acadêmicos brasileiros disponíveis em meio eletrônico na Biblioteca Digital Brasileira de Teses e Dissertações (BDTD), localizada no órgão nacional Instituto Brasileiro de Informação em Ciência e Tecnologia (IBICT). Foram analisados os títulos, resumos, referências e palavras-chaves com indícios de pesquisas sobre biologia celular nos livros didáticos de Ciências e Biologia.

Neste estudo, os trabalhos foram analisados tendo como referência às concepções de ensino: técnica, prática e emancipatória, com base nos pressupostos de Rosa e Shnetzler (2003) (Quadro 1). Buscamos também identificar qual é o papel atribuído ao LD pelos autores das dissertações e teses analisadas. Para isso, recorremos a Choppin (2004), o qual destaca que, dentre as suas múltiplas funções, os LDs exercem quatro que são essenciais: a função referencial, a função instrumental, a função ideológica e cultural e a função documental (Quadro 2).

Quadro 1: Descrição das concepções de ensino aplicadas aos trabalhos analisados.

\begin{tabular}{|l|l|}
\hline \multicolumn{1}{|c|}{ Concepção } & \multicolumn{1}{c|}{ Descrição } \\
\hline Técnica & $\begin{array}{l}\text { Professor: transmissor de saberes e avaliador dos "produtos da aprendizagem"; } \\
\text { Aluno: tábula-rasa - suas manifestações não são consideradas; } \\
\text { Conteúdo: dados a serem transmitidos aos alunos; } \\
\text { Abordagem positivista - a teoria determina a prática. }\end{array}$ \\
\hline \multirow{3}{*}{ Prática } & $\begin{array}{l}\text { Professor: mediador do diálogo e da participação; } \\
\text { Aluno: possui identidade própria; } \\
\text { Conteúdo: os conhecimentos da realidade permitem a comunicação dos sujeitos; } \\
\text { Processo participativo. }\end{array}$ \\
\hline \multirow{5}{*}{ Emancipatória } & $\begin{array}{l}\text { Professor: transforma a educação - promove a problematização, estimulando a } \\
\text { reflexão; } \\
\text { Aluno: Adquire competências e habilidades, é educado para a cidadania. } \\
\text { Conteúdo: é flexível e possível de ser indagado; } \\
\text { Permite a comunicação e a ação social, mediante processos reflexivos. }\end{array}$ \\
\hline
\end{tabular}

Fonte: Adaptado de Rosa e Schnetzler (2003) 
Quadro 2: Descrição das funções do livro didático aplicadas aos trabalhos analisados.

\begin{tabular}{|l|l|}
\hline \multicolumn{1}{|c|}{ Função } & \multicolumn{1}{c|}{ Descrição } \\
\hline Referencial & $\begin{array}{l}\text { Também chamada de curricular ou programática; } \\
\text { O livro didático é apenas uma tradução fiel do programa no qual está inserido, } \\
\text { ele é o suporte privilegiado dos conteúdos educativos, o depositário dos conheci- } \\
\text { mentos, técnicas ou habilidades que um grupo social acredita que seja necessário } \\
\text { transmitir às novas gerações. }\end{array}$ \\
\hline Instrumental & $\begin{array}{l}\text { O livro didático coloca em prática métodos de aprendizagem com a proposta e a } \\
\text { execução de exercícios ou de atividades que, de acordo com o contexto no qual } \\
\text { estão inseridos, visam facilitar a memorização dos conteúdos. }\end{array}$ \\
\hline $\begin{array}{l}\text { Ideológica e } \\
\text { cultural }\end{array}$ & $\begin{array}{l}\text { O livro didático se afirmou como um dos principais vetores da língua, da cultura } \\
\text { e dos valores das classes dirigentes. Ao tornar-se um instrumento privilegiado de } \\
\text { construção de identidade, geralmente é reconhecido como um dos símbolos da } \\
\text { soberania nacional e, nesse sentido, assume um importante papel político. }\end{array}$ \\
\hline Documental & $\begin{array}{l}\text { O livro didático pode fornecer, sem que sua leitura seja dirigida, um conjunto de } \\
\text { documentos, textuais ou icônicos, cuja observação ou confrontação pode vir a } \\
\text { desenvolver o espírito crítico do aluno. }\end{array}$ \\
\hline
\end{tabular}

Fonte: Adaptado de Choppin (2004)

A exploração do material de estudo seguiu os pressupostos de Lüdke e André (2001), desenvolvendo-se em etapas de análise temática de conteúdo, constando de: pré-análise, exploração do material, tratamentos dos dados e interpretação. Na pré-análise utilizamos as palavras-chaves "livro didático" e "célula". Após, os trabalhos selecionados foram novamente classificados por meio da leitura dos resumos. Não houve delimitação temporal na busca, os trabalhos analisados se referem a um período compreendido entre os anos de 2005 e 2018, ou seja, treze anos. Na exploração do material, realizamos a leitura das escritas dos autores categorizando as concepções de acordo com Rosa e Schnetzler (2003) e o papel atribuído ao LD de acordo com Choppin (2004). No tratamento dos dados e interpretação, realizamos a discussão sobre os resultados obtidos contextualizando com o referencial teórico da área. Desse modo, para análise dos resumos, retiramos fragmentos dos textos, que depois passamos a marcações que denominamos concepções, permitindo-nos a análise e construção dos resultados do trabalho. Apresentaremos no próximo item os resultados e a discussão sobre os dados obtidos. 


\section{Resultados e discussão}

Em busca realizada na BDTD pelas palavras-chaves "livro didático" e "célula", foram encontrados 36.471 trabalhos que apresentavam quaisquer das expressões. Após refinada a busca para "todos os termos", foram reduzidos a 31 trabalhos. Por fim, os resumos dos trabalhos foram lidos para avaliar se a temática abordada no trabalho coincidia com o objetivo desta revisão e aqueles que não se enquadravam foram descartados.

Foram encontradas oito dissertações e três teses que atendiam aos objetivos dessa revisão. O Quadro 5 apresenta os trabalhos selecionados de acordo com as seguintes subcategorias: 1- Abreviação dividida em: i) dissertação e ii) tese; 2- Título; 3- Autores; 4- Ano de defesa; e 5- Instituição e local de onde procedem os trabalhos. Assim, para organizar os textos a serem analisados, criou-se um código específico: dissertações "D" e teses "T", seguido de números arábicos correspondentes à ordem cronológica de publicação. É com base na análise dos dados apresentados no quadro que passamos a discutir os resultados produzidos.

Quadro 5: Dissertações e Teses com o tema biologia celular em livros didáticos encontradas na BDTD.

(continua...)

\begin{tabular}{|l|l|}
\hline Código & \multicolumn{1}{c|}{ Referência } \\
\hline D1 & $\begin{array}{l}\text { JOTTA, L. de A. C. V. Embriologia animal: uma análise dos livros didáticos de biolo- } \\
\text { gia do ensino médio. Dissertação (Mestrado em Educação) - Universidade de Brasília. } \\
\text { Brasília, p. 245, 2005. }\end{array}$ \\
\hline D2 & $\begin{array}{l}\text { TAUCEDA, K. C. Aprendizagem de conceitos biológicos através do estudo das re- } \\
\text { presentações mentais. Dissertação (Programa de Pós-Graduação em Educação em } \\
\text { Ciências: Química da Vida e Saúde) - Universidade Federal do Rio Grande do Sul. Porto } \\
\text { Alegre, p. 116, 2009. }\end{array}$ \\
\hline D3 & $\begin{array}{l}\text { CONCEIÇÃO, L. C. S. Abordagem da bioética em âmbito escolar: proposições cons- } \\
\text { tantes de livros didáticos de biologia. Dissertação (Programa de Pós-Graduação em } \\
\text { Ciências e Matemáticas) - Universidade Federal do Pará. Belém, p. 82, 2011. }\end{array}$ \\
\hline D4 & $\begin{array}{l}\text { MARTINS, R. M. A transposição didática do papel termodinâmico do ATP gera con- } \\
\text { ceitos alternativos? Dissertação (Mestrado em Bioquímica) - Instituto de Química, Uni- } \\
\text { versidade de São Paulo. São Paulo p. 90, 2012. }\end{array}$ \\
\hline D5 & $\begin{array}{l}\text { CIRNE, A. D. P. P. Dificuldades de aprendizagem sobre conceitos de genética no } \\
\text { ensino fundamental. Dissertação (Mestrado em Ensino de Ciências Naturais e Matemá- } \\
\text { tica) - Universidade Federal do Rio Grande do Norte. Natal, p. 269, 2013. }\end{array}$ \\
\hline D6 & $\begin{array}{l}\text { HOLANDA, D. X. T. A abordagem de temas contemporâneos de biologia no ensino } \\
\text { médio: um estudo exploratório. Dissertação (Mestrado em Ensino de Ciências e Ma- } \\
\text { temática) - Centro de Ciências, Universidade Federal do Ceará. Fortaleza, p. 164, 2013. }\end{array}$ \\
\hline
\end{tabular}


(conclusão)

\begin{tabular}{|l|l|}
\hline D7 & $\begin{array}{l}\text { PINHEIRO, R. M. de S. O conceito de célula em livros didáticos de biologia: análise } \\
\text { sob uma perspectiva histórico-crítica. Dissertação (Mestrado Educação em Ciências } \\
\text { e Matemática) - Universidade Federal de Goiás. Goiânia, p. 165, 2018. }\end{array}$ \\
\hline D8 & $\begin{array}{l}\text { SANTOS, L. G. dos. Obstáculos epistemológicos presentes nos livros didáticos de } \\
\text { biologia do PNLD 2015: um estudo sobre transporte celular. Dissertação (Mestrado } \\
\text { em Educação em Ciências e Matemática) - Universidade Federal de Goiás. Goiânia, p. } \\
\text { 130, 2018. }\end{array}$ \\
\hline T1 & $\begin{array}{l}\text { FRANZOLIN, F. Conhecimentos básicos de genética segundo professores e docen- } \\
\text { tes e sua apresentação em livros didáticos e na academia: aproximações e distan- } \\
\text { ciamentos. Tese (Doutorado em Educação) - Faculdade de Educação, Universidade de } \\
\text { São Paulo. São Paulo, p. 674, 2012. }\end{array}$ \\
\hline T2 & $\begin{array}{l}\text { WIRZBICKI, S. M. As aprendizagens do conceito energia do metabolismo celular } \\
\text { nas interações entre professores e estudantes mediadas pelos livros didáticos de } \\
\text { biologia do ensino médio. Tese (Programa de Pós-Graduação em Educação em Ci- } \\
\text { ências: Química da Vida e Saúde) - Universidade Federal do Rio Grande do Sul. Porto } \\
\text { Alegre, p. 144, 2015. }\end{array}$ \\
\hline T3 & $\begin{array}{l}\text { NEVES, R. F. das. Abordagem do conceito de célula: uma investigação a partir das } \\
\text { contribuições do Modelo de Reconstrução Educacional (MRE). Tese (Programa de } \\
\text { Pós-Graduação em Ensino das Ciências) - Universidade Federal Rural de Pernambuco. } \\
\text { Recife, p. 264, 2015. }\end{array}$ \\
\hline
\end{tabular}

Fonte: Karas e Hermel (2019)

A partir da análise dos dados foram identificadas duas temáticas de investigação: (i) análise do conteúdo de biologia celular em LDs (7:11) e (ii) discussões acerca da utilização dos LDs no ensino de Ciências/Biologia (4:11). Tanto os autores que analisam o conteúdo de biologia celular em LDs (D1, D2, D3, D4, D7, D8 e T1), quanto os que discutem a utilização dos LDs (D5, D6, T2 e T3) expressam que o LD é “peça fundamental” no processo de escolarização brasileira, sendo um instrumento pedagógico importante ao ensino e, por estar presente na maior parte das escolas, de certo modo é o suporte no processo de formação da sociedade (VASCONCELOS; SOUTO, 2003).

Os trabalhos analisados expressam, em sua maioria, concepções de ensino com caráter emancipatório (7:11), pois defendem a importância da reflexão no processo de ensino e aprendizagem. Os demais (4:11) foram categorizados como práticos, pois defendem a importância da interação entre os sujeitos, mas não reconhecem a relevância da reflexão durante o processo, ao menos não de forma explícita. Não foram encontrados indícios da concepção técnica nos trabalhos analisados (Quadro 3). 
Quadro 3: Concepções de ensino identificadas nos trabalhos analisados.

\begin{tabular}{|l|l|}
\hline \multicolumn{1}{|c|}{ Concepção } & \multicolumn{1}{c|}{ Teses e dissertações } \\
\hline Técnica & - \\
\hline Prática & D1, D4, D8, T1 \\
\hline Emancipatória & D2, D3, D5, D6, D7, T2, T3 \\
\hline
\end{tabular}

Fonte: Karas e Hermel (2019)

Sobre o papel atribuído ao LD pelos autores das dissertações e teses analisadas, foi possível identificar que os trabalhos expressam que o $\mathrm{LD}$ tem função referencial (7:11), o que faz do LD um fiel tradutor do programa curricular, assim como instrumental (7:11), ou seja, o papel do LD é pôr em prática métodos de aprendizagem com atividades e exercícios. E, por fim, a função ideológica e cultural (1:11), pela qual o LD é um vetor de tentativa de afirmação da língua, da cultura e dos valores das classes dirigentes (Quadro 4).

Quadro 4: Funções do livro didático identificadas nos trabalhos analisados.

\begin{tabular}{|l|l|}
\hline \multicolumn{1}{|c|}{ Função } & \multicolumn{1}{c|}{ Descrição } \\
\hline Referencial & $\mathrm{D} 2, \mathrm{D} 5, \mathrm{D} 6, \mathrm{D} 7, \mathrm{D} 8, \mathrm{~T} 1, \mathrm{~T} 2$ \\
\hline Instrumental & $\mathrm{D} 1, \mathrm{D} 2, \mathrm{D} 4, \mathrm{D} 5, \mathrm{D} 6, \mathrm{~T} 1, \mathrm{~T} 2$ \\
\hline Ideológica e cultural & $\mathrm{D} 7$ \\
\hline Documental & - \\
\hline
\end{tabular}

Fonte: Karas e Hermel (2019)

Nenhum trabalho evidenciou a função documental do LD, ou seja, esse material didático não é visto com potencial de desenvolvimento do senso crítico dos alunos. Em alguns dos trabalhos analisados, foi possível identificar mais de uma função atribuída ao LD (D5, D6, D7, T1 e T2), enquanto em D3 e T3 não foi possível identificar o papel atribuído ao LD (Quadro 4). Os excertos discutidos abaixo acentuam os indícios das concepções de ensino e funções atribuídas ao $\mathrm{LD}$, encontradas nos trabalhos analisados.

Em D1, Jotta (2005, [grifos nossos]) realiza uma análise das características das linguagens verbal e visual referentes à embriologia animal, encontradas nos LDs de Biologia, na qualidade de limitadores ou promotores da aprendizagem. Para tanto, foram analisados os textos, quanto ao uso das linguagens figurada, técnico-científica e implícita, e as imagens, quanto à tipologia, à morfologia e à 
funcionalidade. A coleta de dados ocorreu em dez capítulos contidos em oito livros, extraídos de seis coleções de LDs de Biologia destinadas ao Ensino Médio.

A referida pesquisa não discute acerca da importância do diálogo, da interação entre os sujeitos e da reflexão. Apesar disso, a autora manifesta que "[...] o ensino atual da Biologia concentra-se apenas na transmissão de informações, que, em geral, não são incorporadas ao conhecimento dos alunos" (D1, 2005, p. 14). Por conta da crítica realizada pela autora, sua pesquisa foi categorizada como concepção prática. Rosa e Schnetzler (2003, p. 32) colocam que o modelo de ensino prático “[...] é centrado na inserção social do aluno através de um processo participativo, ampliando sua capacidade de apropriação da linguagem científica como mediação na compreensão dos fenômenos".

Ainda, sobre o papel do LD, a autora defende que: "O livro didático, na qualidade de recurso ao qual o aluno pode ter acesso em qualquer momento, deve apresentar todas as explanações que se fazem necessárias à compreensão do conteúdo (D1 2005, p. 93). É possível identificar a função instrumental do LD, sendo este considerado um recurso fundamental para a aprendizagem e integralizado no sentido conceitual e pedagógico.

Tauceda (2009, [grifos nossos]), em D2, avalia a influência das figuras do LD no processo de aprendizagem de conceitos biológicos abstratos (bioquímica e biofísica celular), na construção do pensamento complexo e de modelos mentais. A pesquisa foi desenvolvida com dois grupos, de acordo com a utilização ou não do LD. Nas turmas que utilizavam o LD, a autora constatou uma menor frequência de desenhos que indicavam a construção do pensamento complexo e de modelos mentais, pois, quando foram trabalhadas as figuras do livro, a maioria dos alunos apresentou um retrocesso.

A autora destaca que "[...] a escola faz a transmissão de um saber inerte, ao invés de convocar o estudante a atuar, pensar, criticar, produzir o seu conhecimento através de sua reflexãa sobre o mundo e isso vem estimulando posições passivas nos estudantes" (D2, 2009, p. 87, [grifos nossos]). As expressões grifadas permitiram categorizar a pesquisa em questão como concepção emancipatória, pois estabelece uma crítica às concepções técnicas e enfatiza a reflexão, do mesmo modo que a pesquisa de D3. Rosa e Schnetzler (2003, p. 31) defendem que a concepção emancipatória “[...] investe na possibilidade de superar a limitação dos significados subjetivos 
em direção a um saber emancipador cujo marco de referência objetivo permite a comunicação e a ação social, mediante processos reflexivos".

O papel atribuído ao LD em D2 é referencial e instrumental: “O LD é uma importante fonte de informação para os professores e alunos; é utilizado pelos professores na organização e planejamento das atividades em sala de aula" (D2, 2009, p. 56, [grifos nossos]). Aqui percebemos que a importância do LD se remete ao seu conteúdo e a questão curricular, onde ele aparece como ferramenta organizadora das atividades.

A pesquisa de Conceição (2011, [grifos nossos]), expressada em D3, teve como objetivo explicitar se e como a Bioética é tratada em LD de Biologia do Ensino Médio, bem como analisar de que maneira a abordagem do tema nestes livros contribui para que os estudantes possam conhecê-lo, tornando-se capazes de compreender e refletir, criticamente, sobre o assunto e suas questões no contexto contemporâneo. Além do mais, "[...] o currículo no formato disciplinar já é obsoleto por expressar um caráter mecanicista-memorístico tal que parece difícil ser superado ou descartado em favor das reflexões necessárias a partir daquilo que o estudante já sabe e do contexto no qual ele vive" (p. 31).

De acordo com o autor, a bioética é escassa e demasiadamente superficial na forma como tem sido apresentada nos LDs, deixando de suscitar reflexões por parte do leitor. Dessa maneira, conclui que é imprescindível que os LDs de Biologia passem por uma intensa reformulação no intuito de serem pedagogicamente complementados para acompanharem as mudanças propaladas pelas novas diretrizes e bases do sistema educacional brasileiro.

O autor de D4, Martins (2012, [grifos nossos]), investigou equívocos sobre o papel termodinâmico do ATP nos processos celulares. Os resultados gerais mostram que os estudantes carregam equívocos em conceitos termodinâmicos básicos. Duas possíveis fontes de conceitos alternativos da termodinâmica do ATP são o professor e o LD. Nesse trabalho foi verificado que os livros de Ensino Médio e de graduação podem contribuir para a instalação de conceitos alternativos referentes ao ATP. Nos livros analisados, principalmente os de Ensino Médio, foram encontrados passagens, analogias e esquemas que podem contribuir para isso.

Além disso, o autor aponta entre outras “[...] dificuldades provocadas pelos conceitos alternativos a impossibilidade de utilizá-los para embasar novos conhecimentos [...] os alunos são inconscientemente encaminhados para a memo- 
rização" (MARTINS, 2012, p. 8, [grifos nossos]). Os grifos permitem identificar indícios de uma crítica às concepções técnicas; apesar disso, o texto não apresenta evidências da concepção emancipatória, por isso foi categorizado como prática. Acerca do papel atribuído ao $\mathrm{LD}$, o autor ressalva a função instrumental: “[...] como a principal fonte de consulta dos professores e alunos é o livro didático [...]" (p. 17, [grifos nossos]).

D5, D6 e D7 estabeleceram impressões emancipatórias, pois defendem situações de aprendizagem que possibilitem, além da interação, a reflexão para a construção de conhecimentos aliados ao desenvolvimento de competências e habilidades necessárias para o desenvolvimento de ações sociais.

Cirne (2013, [grifos nossos]), em D5, avaliou as dificuldades de aprendizagem de estudantes do Ensino Fundamental sobre conceitos de genética, em uma escola da rede pública no Estado do RN. As concepções alternativas apontam para origem sensorial, cultural e escolar, principalmente, dos LDs, evidenciadas pela expressão de obstáculos verbais e conhecimento pragmático. De acordo com a autora, é necessário que "[...] o professor promova situações de aprendizagens diversificadas, possibilitando ao aluno o enfrentamento e reflexão do seu conhecimento inicial (ideias prévias) e a construção de um novo conhecimento mais próximo do científico" (p.137, [grifos nossos]). Ainda, a autora propôs uma unidade de ensino potencialmente significativa, visando a contribuir com o planejamento da ação pedagógica do professor, que busca minimizar as dificuldades de ensino e aprendizagem em torno do tema.

Com relação ao papel atribuído ao LD, D5 e D6 expressaram a função referencial e instrumental: "[...] utilização do livro didático como recurso exclusivo para abordagem dos conteúdos pelo professor por transcrição na lousa (D5, 2013, p. 34); “[...] o material didático que tem assumido um ponto referencial nas escolas é particularmente o livro didático, para direcionar a prática pedagógica [...]" (D6, 2013, p. 28, [grifos nossos]).

Em D6, Holanda (2013) analisou de que forma ocorre a abordagem e contextualização de temas biológicos contemporâneos que estão relacionados à Biologia Celular e à Genética, nas aulas de Biologia no Ensino Médio. Os resultados demonstraram que esses conteúdos são pouco abordados em sala de aula, sendo o LD o principal recurso utilizado. Portanto, um dos grandes desafios dos educadores é o de inten- 
sificar o uso de outros materiais e atividades, para além do LD, que auxiliem na condução da aprendizagem.

A autora salienta que uma das dificuldades na aprendizagem é estar na metodologia de resolução repetitiva de questões, em que os alunos “[...] acabam apenas resolvendo problemas propostos como exercícios rotineiros, sem adquirir autonomia e reflexões sobre tais problemas" (D6, 2013, p.25, [grifos nossos]).

Em D7, Pinheiro (2018, [grifos nossos]) analisa como o processo histórico de construção do conceito de célula é apresentado nos LDs de Biologia aprovados pelo Programa Nacional do Livro Didático (PNLD). Os resultados obtidos deixam evidente que a construção do conceito de célula é permeada por meio de uma visão ontológico-mecanicista da Biologia, na qual a Ciência é considerada linear, e a produção científica, uma atividade individual. Sendo assim, “[...] esses livros precisam integrar os conhecimentos por meio da contextualização, valorizando a função social da escola e promovendo a construção e reflexão crítica dos conceitos científicos" (p.125, [grifos nossos]). Com isso, a pesquisa contribui para desvelar o LD como um recurso didático que pode levar a um trabalho docente alienante, já que revela o modo de apresentação do conhecimento, que pode ser acrítico e a-histórico. As funções atribuídas ao LD em D7 são referenciais e ideológica e cultural:

“O LD é 'peça fundamental' no processo de escolarização brasileira, sendo parte da cultura e lembranças de muitas gerações. Sendo assim, é instrumento pedagógico importante ao ensino e, por estar presente na maior parte das escolas, de certo modo é o suporte no processo de formação da sociedade" (D7, 2018, p. 45, [grifos nossos]).

A pesquisa de Santos (2018, [grifos nossos]), em D8, se constitui de reflexões crítico-teóricas sobre a importância que os conceitos de Transporte Celular têm para o ensino e aprendizagem de Biologia no Ensino Médio através de um recurso pedagógico muito presente na prática escolar, o LD. O objetivo era elucidar, a partir da análise de elementos conceituais e ilustrativos referentes ao conteúdo de Transporte Celular, os possíveis obstáculos epistemológicos cunhados por Bachelard.

A não compreensão dos mecanismos de funcionamento do Transporte Celular, ainda no primeiro ano do Ensino Médio, pode contribuir para a geração de visões simplificadas e deturpadas acerca do conhecimento biológico e que poderão acompanhar os alunos, não apenas ao longo de sua trajetória escolar ou acadêmica, mas ao longo de suas vidas. $O$ autor conclui, a partir do exame de nove obras, que 
há incidência de vários obstáculos epistemológicos nos LDs de Biologia do PNLD 2015, com ênfase nos obstáculos animista e realista.

Os autores de D8 e T1 apresentaram sinais da concepção prática, pois discutem sobre os processos de ensino e de aprendizagem que ocorrem através da interação entre os envolvidos e estabelecem críticas aos modelos tradicionais de ensino, porém sem aproximar-se das necessidades de reflexões. Da mesma forma, com relação ao papel atribuído ao LD, D8 e T1 expressam a função referencial: “[...] o livro didático é ainda o principal instrumento de trabalho do professor, pois é a partir deste que são elaborados os planejamentos mensais e anuais, bem como o plano de aula" (D8, 2018, p. 18, [grifos nossos]). T1 apresenta também a função instrumental: “[...] a importância do livro didático na determinação do que é hoje em dia ensinado pelo professor" (T1, 2012, p. 48).

Franzolin (2012, [grifos nossos]), em T1, identificou os conhecimentos básicos sobre Genética para a formação de cidadãos críticos no Ensino Médio e também verificou como, ao estarem presentes nos LDs, os conhecimentos considerados básicos sobre Genética se aproximam e se distanciam dos saberes acadêmicos. Foram analisados os conteúdos Meiose, Leis de Mendel e Expressão gênica.

Os resultados apontam que, para muitos entrevistados, os conteúdos considerados como básicos são importantes para que os alunos compreendam informações recebidas em seu cotidiano e a expressão de suas próprias características. Entretanto, questiona-se aqui se não seria importante mais ênfase em conteúdos relacionados à expressão de características complexas. Conclui-se que, na amostra analisada, as aproximações são mais frequentes do que os distanciamentos, possivelmente, devido ao maior rigor com relação ao conhecimento científico, por causa da influência das avaliações de LDs.

Por fim, T2 e T3 evidenciam as concepções emancipatórias, pois destacam a importância da reflexão crítica nas interações escolares para que os envolvidos desempenhem papéis de cidadãos na sociedade, superando assim o modelo prático.

A pesquisa de Wirzbicki (2015, [grifos nossos]), em T2, investigou que evidências de aprendizagens do conceito "energia do metabolismo celular" podem ser identificadas no ensino de Biologia no Ensino Médio, a partir da interação professor e aluno mediada pelo LD. De acordo com a autora, as explicitações do conceito nos LDs, em sua maioria, estão distantes das concepções dos professores e das compreensões dos estudantes, constituindo obstáculos à aprendizagem. 
Ainda, a autora destaca que a relação dos docentes com os saberes não se reduz a uma função de transmissão de conhecimentos já instituídos. A prática necessita de reflexões críticas e muito estudo acerca de limitações e potencialidades do professor e dos estudantes com quem interage. Com relação ao papel atribuído ao LD, Wirzbicki (2015, p. 103, [grifos nossos]) aponta que:

[...] "o LD orienta os planejamentos e as ações mediadas pelo professor em sala de aula. Esquece-se que este material foi pensado como um suporte didático para que o aluno tenha acesso aos conceitos em momentos distintos ao da sala de aula, que tenha no LD uma fonte de pesquisa, um recurso, mas não um orientador curricular."

Neves (2015, [grifos nossos]), em T3, investigou a abordagem do conceito de célula com licenciandos em Ciências Biológicas, mediante a utilização do Modelo de Reconstrução Educacional. De acordo com o autor, nas Ciências Biológicas, propostas como o Modelo de Reconstrução Educacional são promissoras no processo de ensino e de aprendizagem, visando a mudanças na construção de conceitos.

O autor salienta que, "[...] ao abrir oportunidade para esses temas, eclodem naturalmente as discussões e reflexões, permitindo que os indivíduos debatessem e se posicionassem com criticidade, refletindo sobre as propostas, exercendo seu papel de cidadãos" (p. 220).

Questionar, problematizar e refletir são exercícios importantes para a formação crítica do ser humano. Quando tratamos do ensino de biologia celular, a relevância torna-se ainda maior. Conforme destaca Schein e Coelho (2006, p. 70): "o professor que se identifica com uma postura epistemológica construtivista cria espaço para o desenvolvimento de pesquisa e elaboração de questionamentos em sala de aula". Podemos salientar, nesse contexto, que há uma grande importância em perfis como este apresentado e que é encontrado na maioria dos trabalhos analisados, afinal a educação e a formação crítica se constroem através das interações e reflexões promovidas entre os envolvidos.

\section{Considerações finais}

A biologia celular nos LDs é pouco abordada em teses e dissertações, sendo que esse tipo de análise é fundamental para uma melhoria no processo de ensino e aprendizagem. Um bom entendimento sobre o que é uma célula é fundamental 
para compreender os demais conteúdos de biologia, além de permitir a noção e o posicionamento crítico em assuntos cotidianos.

Apesar disso, com relação às concepções de ensino analisadas, os resultados apontaram para uma tendência emancipatória - que problematiza os conhecimentos científicos. Assim, as aulas estimulam a reflexão, o raciocínio e a autonomia, preparando os sujeitos para a tomada de decisões e a vida em sociedade.

Em relação ao papel atribuído ao $\mathrm{LD}$, foi possível identificar que ele está diretamente relacionado com o currículo escolar, sendo quem determina o que será estudado, quando e como. Os LDs fazem parte das políticas públicas relacionadas ao ensino e os conteúdos que abrangem são determinados e, em muitos casos, determinantes do currículo nessas políticas.

Além disso, outra função que prevaleceu foi com relação ao papel instrumental do $\mathrm{LD}$, sendo que a execução de exercícios ou de atividades contidas nele visam a facilitar a memorização dos conteúdos.

Percebemos a necessidade de mais estudos sobre o processo de ensino e de aprendizagem de biologia celular mediado pelo $\mathrm{LD}$, visto que esta é uma das ferramentas mais utilizadas no contexto escolar. Os LDs precisam ir ao encontro do ensino emancipatório e permitindo que os alunos consigam superar suas limitações e encontrem nele uma fonte que estimule as reflexões e a construção de conhecimentos científicos através dos questionamentos e da relação com o cotidiano dos alunos.

\section{Cell in biological education: the role of the teaching book and teaching conceptions}

\section{Abstract}

The cell is the smallest structural and functional unit of different living organisms, being able to exist independently. All living things are made up of one or several cells that are extremely small, so it is only possible to analyze, understand and study with the aid of a microscope. Textbooks are one of the most widely used tools in schools by both students and teachers. The content of cell biology is presented in a detailed and richly illustrated way in textbooks, so it is essential to know what recent research points about the study of cell biology mediated by the textbook. For this, the present research of documentary and bibliographic character analyzed the conceptions of teaching of cellular biology and the role attributed to the textbook in eight dissertations and three theses. Over the conceptions of teaching there was a predominance of the emancipatory conception, followed by practice. There was no evidence of technical design. The results point to a teaching tendency based on the interaction between the subjects mediated by reflexive 
processes. Regarding the role attributed to the textbook, it was possible to identify that the works express that it has a referential and instrumental function, that is, the role of the textbook is to put into practice learning methods with activities and exercises, being a faithful translator of the curriculum.

Keywords: cell biology, curriculum, science education.

\section{Referências}

AMARAL; I. A. do; MEGID NETO, J. Qualidade do livro didático de Ciências: o que define e quem define? Ciência \& Ensino, Campinas, n. 2, p. 13-14, 1997.

CHOPPIN, A. História dos livros didáticos e das edições didáticas: sobre o estado da arte. Educação e Pesquisa, São Paulo, v. 30, n. 3, p. 549-566, set/dez. 2004.

CIRNE, A. D. P. P. Dificuldades de aprendizagem sobre conceitos de genética no ensino fundamental. Dissertação (Mestrado em Ensino de Ciências Naturais e Matemática) - Universidade Federal do Rio Grande do Norte. Natal, p. 269, 2013.

CONCEIÇÃO, L. C. S. Abordagem da bioética em âmbito escolar: proposições constantes de livros didáticos de biologia. Dissertação (Programa de Pós-Graduação em Ciências e Matemáticas) - Universidade Federal do Pará. Belém, p. 82, 2011.

DÍAZ, Omar, R. T. A atualidade do livro didático como recurso curricular. Linhas Críticas, Brasília, DF, v. 17, n. 34, p. 609-624, set./dez. 2011. Disponível em: <https://sbenbio.org.br/ wpcontent/uploads/edicoes/revista_sbenbio_n9.pdf>. Acesso em: 18 jan. 2020.

FRANZOLIN, F. Conhecimentos básicos de genética segundo professores e docentes e sua apresentação em livros didáticos e na academia: aproximações e distanciamentos. Tese (Doutorado em Educação) - Faculdade de Educação, Universidade de São Paulo. São Paulo, p. $674,2012$.

GUIMARÃES, F. M.; MEGID NETO, J.; FERNANDES, H. L. Como os professores de $6^{\circ}$ ao $9^{\circ}$ anos usam o livro didático de Ciências. In: Encontro Nacional de Pesquisa em Educação em Ciências, 8., 2011, Campinas. Anais... Campinas: UNICAMP, 2011. Disponível em: <http://www.nutes.ufrj. br/abrapec/viiienpec/resumos/R0977-1.pdf>. Acesso em: 11 abr. 2020.

HOLANDA, D. X. T. A abordagem de temas contemporâneos de biologia no ensino médio: um estudo exploratório. Dissertação (Mestrado em Ensino de Ciências e Matemática) - Centro de Ciências, Universidade Federal do Ceará. Fortaleza, p. 164, 2013.

JOTTA, L. de A. C. V. Embriologia animal: uma análise dos livros didáticos de biologia do ensino médio. Dissertação (Mestrado em Educação) - Universidade de Brasília. Brasília, p. $245,2005$.

JUNQUEIRA, L.C.U.; CARNEIRO, J. Biologia celular e molecular. 9ª̣ed. Rio de Janeiro: Guanabara Koogan, 2012.

LÜDKE, M.; ANDRÉ, M. E. D. A. Pesquisa em educação: abordagens qualitativas. São Paulo: EPU, 2001. 38p. 
MARTINS, R. M. A transposição didática do papel termodinâmico do ATP gera conceitos alternativos? Dissertação (Mestrado em Bioquímica) - Instituto de Química, Universidade de São Paulo. São Paulo p. 90, 2012.

NEVES, R. F. das. Abordagem do conceito de célula: uma investigação a partir das contribuições do Modelo de Reconstrução Educacional (MRE). Tese (Programa de Pós-Graduação em Ensino das Ciências) - Universidade Federal Rural de Pernambuco. Recife, p. 264, 2015.

NUÑEZ, I. B.; RAMALHO, B. L; SILVA, I. K. P. da. CAMPOS, Ana Paula N. A seleção dos livros didáticos: um saber necessário ao professor. $\mathrm{O}$ caso do ensino de ciências. Revista Iberoamericana de Educación (Online), www.campus-oei.org, v. -, p. 1-15, 2003.

OCCELLI, M.; VALEIRAS, N. Los libros de texto de ciencias como objeto de investigación: una revisión bibliográfica. Revista Enseñanza de las Ciencias, Barcelona, v. 31, n.2, 2013.

PINHEIRO, R. M. de S. O conceito de célula em livros didáticos de biologia: análise sob uma perspectiva histórico-crítica. Dissertação (Mestrado Educação em Ciências e Matemática) - Universidade Federal de Goiás. Goiânia, p. 165, 2018.

ROSA, M.I.F.P. S.; SCHNETZLER, R. P. A investigação-ação na formação continuada de professores de ciências. Ciência e Educação, Bauru, v. 9, n.1, p. 27-39, 2003. Disponível em: http:// www.scielo.br/pdf/ciedu/v9n1/03.pdf. Acesso em: 11 jun. 2019.

SANTOS, L. G. dos. Obstáculos epistemológicos presentes nos livros didáticos de biologia do PNLD 2015: um estudo sobre transporte celular. Dissertação (Mestrado em Educação em Ciências e Matemática) - Universidade Federal de Goiás. Goiânia, p. 130, 2018.

SCHEIN, P; COELHO, S. O papel do questionamento: intervenções do professor e do aluno na construção do conhecimento. Caderno Brasileiro de Ensino de Física, Universidade Federal de Santa Catarina, Santa Catarina, SC, v. 23, n. 1, p. 68-92, abr. 2006. Disponível em: https:// bit.ly/2PLUCPh. Acesso em: 15 jun. 2019.

TAUCEDA, K. C. Aprendizagem de conceitos biológicos através do estudo das representações mentais. Dissertação (Programa de Pós-Graduação em Educação em Ciências: Química da Vida e Saúde) - Universidade Federal do Rio Grande do Sul. Porto Alegre, p. 116, 2009.

VASCONCELOS, S. D.; SOUTO, E. O livro didático de ciências no ensino fundamental - Proposta de critérios para análise do conteúdo zoológico. Ciência \& Educação, Bauru, v. 9, n.1, p. 93 - 104, 2003.

WIRZBICKI, S. M. As aprendizagens do conceito energia do metabolismo celular nas interações entre professores e estudantes mediadas pelos livros didáticos de biologia do ensino médio. Tese (Programa de Pós-Graduação em Educação em Ciências: Química da Vida e Saúde) - Universidade Federal do Rio Grande do Sul. Porto Alegre, p. 144, 2015. 